\title{
Islamic Vocabulary Enrichment for Autistic Children through Visual Support
}

\author{
$1^{\text {st }}$ Rohmani Nur Indah ${ }^{1}, 2^{\text {nd }}$ Galuh Nur Rohmah ${ }^{1}$ \\ \{ indah@bsi.uin-malang.ac.id ${ }^{1}$, galuhnurrohmah@yahoo.com ${ }^{1}$ \} \\ Universitas Islam Negeri Maulana Malik Ibrahim, Jalan Gajayana 50 Malang, 65145, Indonesia ${ }^{1}$
}

\begin{abstract}
For children, vocabulary enrichment needs exposure as it is related to several factors including the role of parents to facilitate their increase in both receptive and expressive vocabulary. This paper discusses language of autistic children and the use of visual support to facilitate vocabulary enrichment related to Islamic terms. It explores the visual support used by teachers of a primary school for special need students in Malang, Indonesia. The finding shows that teachers employed several types of visual support used as teaching media during both one-on-one learning and class interaction with the purpose of vocabulary enrichment. One of the set of vocabularies students need to acquire is religion related terms that in this paper concerns with Islamic vocabulary, some of which are loan words from Arabic language. Therefore, acquiring Islamic vocabulary is not always easy especially when it is introduced to children with special need or those with specific language impairment. Some suggested techniques are also given when implementing visual support to introduce Islamic vocabulary to students with special needs.
\end{abstract}

Keywords: autism; Islamic vocabulary; special need students; visual support

\section{Introduction}

Vocabulary enrichment belongs to a big task for children as they need to build meaningful relationships among words. They need help to understands words as they relate to concepts and further they should develop it through self learning process [1]. It is not about loading words in the gigantic storage in their mind because vocabulary enrichment also concerns with how children add, organize, use and reuse their daily vocabulary.

Autistic children struggle to cope with the various daily vocabulary that always develop in numbers and usage. They have difficulties to relate the vocabulary with their understanding as they have different ability to acquire language syntactically and pragmatically [2]. However, it does not mean that they have limitation to learn about Islam [3].

Acquiring vocabulary is one of the biggest challenges for autistic children in learning the second language. Meaningful and contextualized vocabulary will guide them to have a great improvement in their vocabulary growth. With contextualized vocabulary, they are able to make connection between the vocabulary and its usage in daily life.

\section{Literature Review}




\subsection{Children Vocabulary Acquisition}

Children vocabulary acquisition deals with several factors such as age of acquisition, frequency of conversation and parental vocabulary [4]. It shows that despite the language introduced to the children, acquiring the vocabulary is related to the role of parents not only to model the language but also to facilitate them to enrich their vocabulary using several supports.

There are some risk factors such as non- English speaking background, low school readiness, low reading habit, more siblings, low family income, low maternal education, maternal mental health distress, and low maternal parenting consistency exist in children vocabulary acquisition [5]. It indicates that those social elements in children's developmental outcomes increase over time. Despite of those social elements, multiple cognitive and language skills were directly related to vocabulary acquisition. Furthermore, working memory and attention also made indirect contributions [6]. In this context, introducing Islamic vocabulary to children with language difficulties should start from the basic level within the level of their understanding.

\subsection{Islamic Vocabulary}

Children learn vocabulary related to their daily life. The concept they need to acquire involves religion related words. In this case, such vocabulary commonly consists of abstract words which are not easy to acquire. Acquiring nouns or words in this context might also require different languages, for instance in Islamic vocabulary some terms belong to loan words from Arabic language. While children in general longitudinally acquire or develop their first vocabulary that formulated in Verb-Subject-Object word order and semantically rich preposition [7]. Their vocabulary on religion terms are also built through this pattern. A systematic and structured contextualized word family model on children's vocabulary acquisition results in a statistically significant improvement [8].

\section{Methods}

The participants of this study is ten teachers of a primary scholl for special need students in Malang. The selected teachers are those with at least five years teaching experience and have certificate on teaching special need students. They were interviewed on the information concerning their difficulty in teaching special need students particullarly those with autistic spectrum disorder, their experience in teaching language and religion to these students, and their expectations for the learning programs.

This study employed a general inductive approach that provides systematic procedure for analyzing qualitative data which are in the form of interview result and documentation of teaching instruments. In doing data reduction, the focus is on describing the complex data through establishment of summary themes [9]. The result of this procedure is to capture the key aspects to be analysed further in terms of the teacher's experience in teaching language and religion using the teaching media for students with special need.

\section{Visual Support For Autistic Children}




\subsection{Language of Autistic Children}

Teachers reported that their students are mostly emphasis on non verbal communication rather than verbal expression. It shows that autistic children have special linguistic function regarding their specific communicative engagement. In this case, it would be a big difference between "literal language" and "concrete thinking" among persons with autism [10]. The later is easier for these children to cope with.

Another feature of their communication is predictable conversation or interaction flow. Most teacher agreed that their expressions are monotonous, easily predicted as they tend to repeat similar responses. This is obvious that these special need children have formulaic expression or formulaic language [11]. Teachers believe that it can be a shortcoming as well as highlight when it is related to vocabulary enrichment. The shortcoming lies in limitation to develop conversation but the highlight is they will use consistent vocabulary that they are familiar with. For example when they were introduced to the sequence of wudhu, the students will recall consistent words as told in the drills.

However it is understandable that the language acquisition including the vocabulary improvement varied among the students. Accordingly, treating the language difficulties of children with autism is not only based on their Autistic-spectrum Quotient (AQ) but also on the domination of lateralisation. Therefore understanding their ability in language supports the notion of autism as continuum, not as categorical diagnosis [12].

\subsection{Visual Support for Autistic Children}

Visual support is highly recommended for developing the communication ability and assisting the children to understand as well as to express themselves. As reported in the interview session, teachers commonly believe that the success of their teaching is really determined by the support from the parents. Some of the teachers shared the media of visual support with the parents to be practised at home. Student's communication ability is significantly influenced by parent's role for instance using visual support to tell stories that will be more emotionally available to these children [13].

Another reason why visual support is more beneficial concerns with the main feature of autistic children namely visual learners. These children are very good in their visual despite their poor listening skill. They are often thought to be deaf as well as hard to be listenable to people [14]. They are obviously respond better using pictorial cues rather than verbal cues [15]. Accordingly they need more playfully receptive tools in communication, one of which is visual support engaged in various contexts.

It must be highlighted that language disorder in autistic children does not have relation to dysphasia combined with visual impairment causing failure to develop visual language system [16]. The use of visual support can help them to encounter their language difficulty in general since there is not specific deficit in language such as what assumed earlier in some studies [17]. Therefore, the use of visual support is very potential when it is integrated to various learning goals, for instance to enrich the vocabulary on Islamic terms.

Not only for language support, visual tools can be used for several purposes, for instance through social story to prevent autistic children from tantrum as a behavioral intervention [18]. This strategy is effective as reported by most teachers using visual media. Once the behavior can be controlled well, it can facilitate the learning to develop several basic skills such as social functioning and practical communication. 
Stories and songs have been popular and effective resources in the special need school. Listening to stories, songs and the combination of both have great effect on children's vocabulary growth. However, the story affected the highest scores and the most effective [19].

For children with special needs, increasing receptive vocabulary belongs to the initial stage of developing literacy skills that requires special technique in reading intruction [20]. Reading instruction by merely focuses on verbal command is not effective. Some suggested techniques cover the use of sign language, modelling, prompt and visual support.

Visual support can help bridging the gap between literal language and concrete thinking [10] by taking part to aid transition in a communication setting. For instance when autistic children need to understand an instruction, it can be used as a transition between the verbal instruction or command with the phisical transition prompt [21]. In addition, visual supports in handled electronics such as handphone or tablet are also effective for autistic children aged 8 to 14 to increase the use of verbs and nouns [22].

\subsection{Visual Support on Islamic Vocabulary}

Visual support based on the teaching experience reported is effective not only for autistic children but also to students with other difficulties. This tool also woks well with those with specific language impairment [23]. It gives significant benefits to working memory performance especially when it is employed in the context of learning for various purposes, including learning to enrich vocabulary in Islam. Therefore, teachers stated that preparing visual support for any classes becomes a priority to support student's learning.

Autistic children with deficits in social understanding need various techniques in their intervention programs. Visual support applied in portraiture-based intervention can be used to improve their understanding on social functioning [24]. This aspect also includes how to understand the social practices related to religion. Another technique such as portrait drawing session also has a great potential to be an intervention for ASDs children developing communication and vocabularies [25].

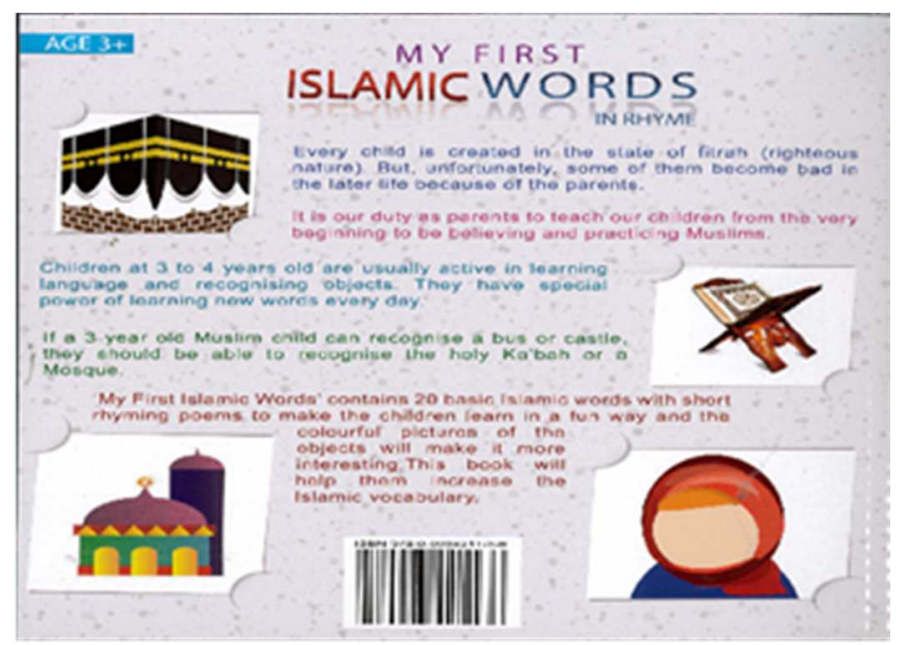

Figure 1. First Islamic words

First Islamic vocabulary for children with or without language difficulties is characterized by concrete words which are observable and easy to visualize through pictures. The difference 
is on the way to present the visual information. For autistic children the vocabulary is given one by one based on the order of familiarity, for instance familiarizing the word mosque (masjid) in first day followed by the Koran on the next day. Then introducing hijab for girls and some other Islamic outfits in different meetings. In the poster of fig. 1, Ka'bah is introduced the last as it is not available in their surrounding [26]. In this case teacher cannot rely on one poster as the students need more visual support.Teacher can make use of photos or videos on ka'bah available online.

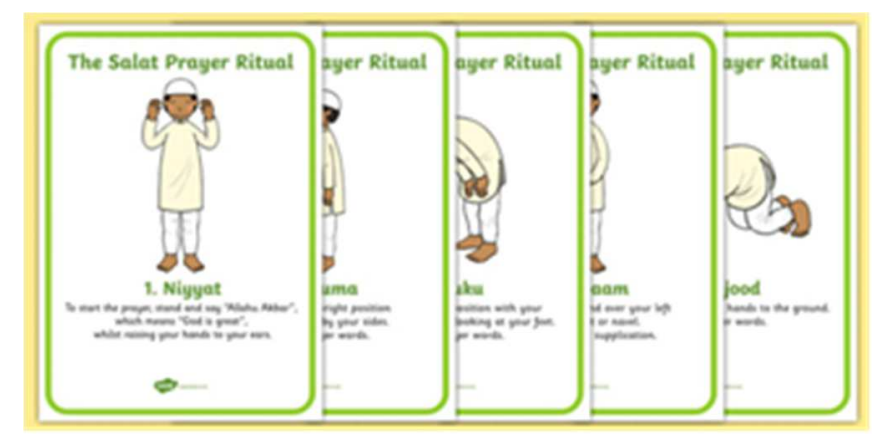

Figure 2. Procedural action words

Teaching some vocabularies involved in Islamic prayer is also a special challenge as prompting is not enough. In this case, the use of visual support is necessary as bridging between the verbal instruction to do salat and its actual prompt. For instance to introduce niyyat and takbiratul ihram is given with the combination among modelling-verbal instructionvisual support-actual prompt-practice. The set of procedural action words using cue cards [27] are presented in a fixed order, for instance the procedural action words on taking ablution (wudhu) are given before those on salat. On salat, the understanding of its procedure is required before teaching the procedure for jama'ah prayer. Then the next step is introducing procedural action words for praying at the mosque. However teaching procedural action words using cue cards only is not enough. Teacher can add the visual support with photos or videos available online. 


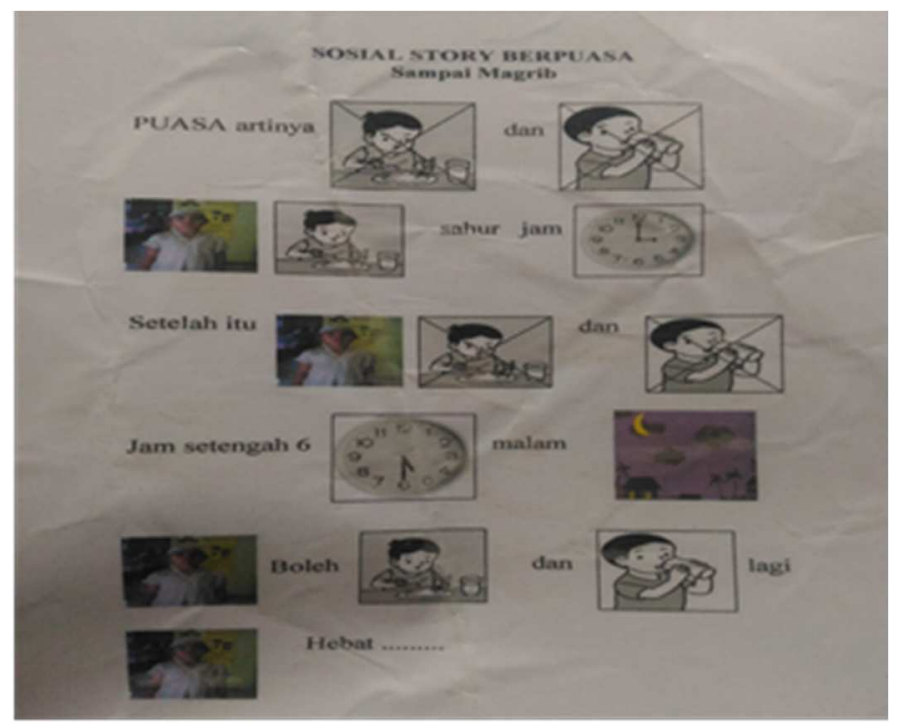

Figure 3. Social story on fasting

Islamic vocabularies are not only words relevant to Islam but also on worship (ibadah). Abstract word such as fasting needs elaboration on several aspect such as what it does not deal with, when it is done and how to do it. Fig. 3 illustrates the social story on fasting during Ramadhan month. Fasting is defined in simplest way by using the pictures. For the advanced learners the definition of fasting that also involves preventing from anger also can make use of social story. Some pictures available online might not be exactly the same with the targetted words, accordingly teacher can also use photo of the student's context to be more realistic. The social story on fasting can be completed with other vocabulary target such as sahur, adzan, niyyat for fasting, tarawih prayer and so on.

Not all Islamic vocabulary can be taught directly, for example in describing aurat as private part of body to uncover or unexposed, the social story should begin with the verb not the noun of the words. The consequence of defining aurat is not to touch as it is prohibited. Therefore in fig. 4 the goal of the social story is not defining what aurat is but to build understanding that it is socially unacceptable to touch somebody else's aurat. The intervention of such a social story is more effective when it is relevant to the current situation of the learner. For the case in fig. 4 , the social story is used as a behavior intervention that indirectly will firther support the goal to enrich student's vocabulary on the word aurat. 


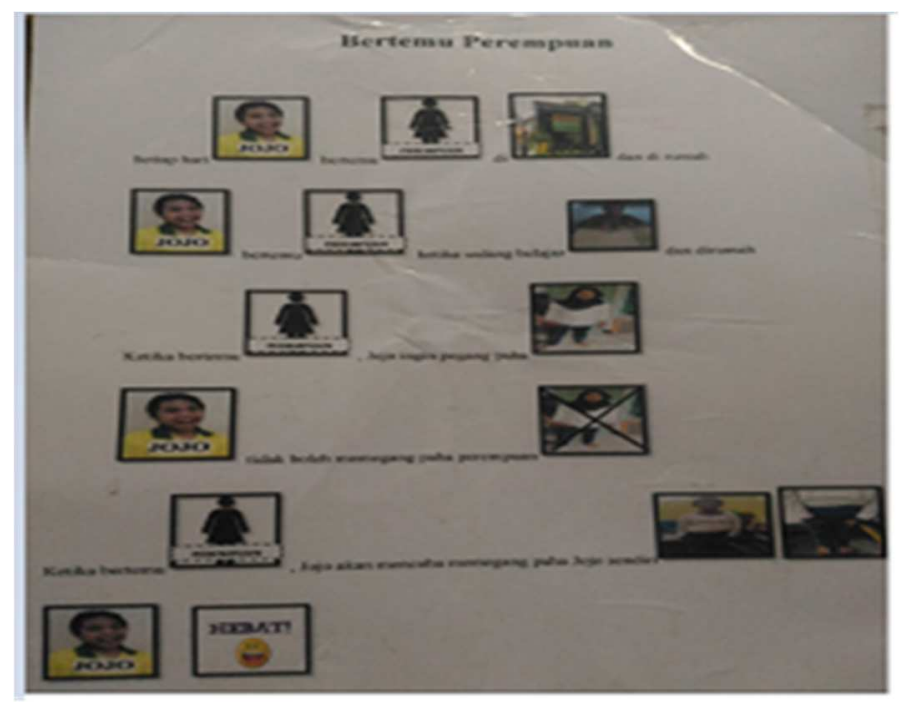

Figure 4. Social story for intervention

However, the use of visual support also has limitation, for instance to describe proper name which in Islam it belongs to infinity. Therefore the teaching of specific abstract vocabulary still relies on formulaic expression. The following is an excerpt of formulaic question-answer of an autistic student (JJ) and his teacher:

T: H* JJ, siapa तע nama Tuhanmu? (Who's your God?)

S: (.) Allah

T: Siapa 기 nama Nabimu? (Who's your messenger?)

S: (.) Muhammad

T: L\% Bagus, $H^{*}$ anak hebat (Great, good boy)

In the formulaic conversation above, teacher addressed the student's name using high pitch to gain his attention. Asking "who" uses rising intonation and ends with longer falling intonation. The student needs pause to answer each question. Different word order such as Nama Tuhanmu siapa JJ? (Your God's name, JJ?) will not be responded similarly as it violates the formula. The formulaic conversation ends with compliment in lower pitch then higher pitch sometimes with clapping altogether. This conversation is repeated several times for retention.

\section{Conclusion}

The use of visual support for acquiring vocabulary is considered as effective technique for vocabulary growth. At-risk children involving those with special need and those with specific language impairment, visual support has helped them to contextualize the vocabulary for dayto-day usage. Visual support strengthens autistic children's working memory to process the vocabulary. The systematic pattern from visual support facilitates the autistic children to the connected sequence of vocabulary. Then, repeated action of the sequence familiarizes autistic children with similar pattern which is beneficial for the retention. 
Acquiring Islamic vocabulary from visual support exposes autistic children with their sociocultural context in term of religion practices. Meanwhile, it also simultaneously provides multiple effects on the ability to find the bridge between the new vocabulary and their daily practice, on fully communicative engagement, and on social understanding. The use of procedural action words and social story can transform the acquisition into positive learning environments where autistic children academically, socially, and emotionally settled. Providing autistic children with structured visual support creates a sense of connection as one of bases for vocabulary growth and development of their communication skill.

Teaching Islamic vocabulary provides some challenges when it deals with abstract ideas. Visual support should carefully designed and given. Therefore, the implications should be taken into consideration for enriching autistic children's vocabulary are the sequence of the visual support and the operationalization of the vocabulary to autistic children real life. The use of visual support through procedural action words and social story for vocabulary enrichment is not free from limitation. Further researches on other diverse visual supports will be worth-investigating.

Acknowledgements. This paper in conjuction with The 1st International Conference on Islam, Science and Technology (ICONIST 2018) in Malang, East Java.

\section{References}

[1] C. Westby "Building children's vocabulary" Child Language Teaching and Therapy vol. 26 no. 12014.

[2] R. N. Indah. Gangguan Berbahasa. UIN Press. Malang. 2017.

[3] R. N. Indah. Introducing Islam to children with special need. Presented at International Conference on Islamic Education in Southeast Asia, 3-5 December 2015, Faculty of Tarbiyah and Teaching Training Maulana Malik Ibrahim State Islamic University.

[4] D. Bleses, W. Vach \& P. S. Dale "Self-reported vocablary input frquency for young children" Journal of Child Language vol. 45 no. 52018.

[5] C. L. Taylor, D. Christensen, D. Lawrence, F. Mitrou, S. R. Zubrick, "Risk factors for children's receptive vocabulary development from four to eight years in the longitudinal study of Australian Children PLoS One; San Francisco vol. 8 no. 92013.

[6] G. K. Young-Suk "Multicomponent view of vocabulary acquisition: An investigation with primary grade children. Journal of Experimental Child Psychology vol. 162, pp. 120-133 2017

[7] C. O'toole \& P. Fletcher. Profiling vocabulary acquisition in Irish. Journal of Child Language, vol 39 no. 1, pp.205-220 2012

[8] F. Subon. "Direct vocabulary instruction: the effects of contextualised word families on learners' vocabulary acquisition” Procedia - Social and Behavioral Sciences vol. 224 , pp. $284-291$ 2016.

[9] D. Thomas "A general inductive approach for analyzing qualitative evaluation data". American Journal of Evaluation vol. 27 no.2, pp. 237-246 2006.

[10] R. P. Hubson. "Autism literal language and concrete thinking:some developmental considerations" Metaphor and Symbol vol 27 no. 1, pp. 4-21 2012.

[11] S. Dobbinson, M. Perkins \& J. Boucher. "The interactional significance of formulas in autistic language" Clinical Linguistics \& Phonetics vol. 17 no. 3-4, pp. 299-307 2009.

[12] A. K. Lindell, K. Notice \& K. Withers "Reduced language processing asymmetry in nonautistic traits" Laterality: Asymmetries of Body, Brain and Cognition vol. 14 no. 5, pp. 457-472 2009. [13] C. Urwin "A psychoanalytic approach to language delay: when autistic isn't necessarity autism” Journal of Child Psychotherapy vol. 28 no.1 pp. 73-93 2010. 
[14] A. Alvarez. "Finding the wavelength: tools in communication with children with autism" Infant Observation vol. 7 no.2-3, pp. 91-106 2004.

[15] E. A. West "Effect of verbal cues versus pictorial cues on the transfer of stimulus control for children with autism" Focus on Autism and Other Developmental Disabilities vol. 23 no. 4, pp. 2292412008.

[16] J. Boucher "Is autism primarily a language disorder?" British Journal of Disorders of Communication vol. 11 no. 2, pp. 135-143 2009.

[17] M. A. Gernsbacher \& S. R. Pripas-Kapit "Who's missing the point? A commentary on claims that autistic persons have a specific deficit in figurative language comprehension" Metaphor \& Symbol vol. 27 no 1, pp. 93-105 2012.

[18] P. A. Lorimer, R. L. Simpson, B.S. Myles, J. B. Ganz "The use of social stories as a preventative behavioral intervention in a home setting with a child with autism" Journal of Positive Behavior Interventions vol. 4 no.1, pp. 53-60 2002.

[19] S. A. Albaladejo, Y. Coyle, J. R. de Larios "Songs, stories, and vocabulary acquisition in preschool learners of English as a foreign language" System vol. 76, pp. 116-128 2018.

[20] L. Beechre \& A. Childre "Increasing literacy skills for students with intellectual and developmental disabilities: effects of integrating comprehensive reading instruction with sign language" Division on Autism and Development Disabilities vol. 47 no. 1, pp. 487-501 2012.

[21] S. Dettmer, R. L. Simpsin, B. S. Myles, J. B. Ganz "The use of visual supports to facilitate transitions of students with autism" Focus on Autism and Other Developmental Disabilities vol. 15 no. 3, pp. 163-1692000.

[22] J. B. Ganz, M. B. Boles, F. D. Goodwyn, M. M. Flores "Efficacy of handled electronic visual supports to enhance vocabulary in children with ASD" Focus on Autism and Other Developmental Disabilities vol. 29 no. 1, pp. 3-12 2013

[23] M. Quail, C. Williams \& S. Leitao "Verbal working memory in Specific Language Impairment: the effect of providing visual support" International Journal of Speech-Language Pathology vol. 11 no.3, pp. 220-233 2009

[24] B. Levin "Portraiture and social understanding" Advances in Autism vol. 1 no.1, pp.30-40 2015.

[25] Y.B. Cheng, A. Salleh, and K. Jusoff "Portrait drawings therapy: windows of hope for children with autism spectrum disorder" World Applied Sciences Journal (Learning Innovation and Intervention for Diverse Learners) vol. 14 no. 1, pp. 44-51 2011.

[26] My first Islamic words (http://www.darumakkah.com/product/my-first-islamic-words-by-kuddin-pb/)

[27] The shalat prayer ritual posters (https://www.twinkl.co.uk/resource/t-t-2212-the-salat-prayerritual) 